\title{
Espoliação urbana e insurgência: conflitos e contradições sobre produção imobiliária e moradia a partir de ocupações recentes em São Paulo
}

\author{
Urban dispossession and insurgency: conflicts and contradictions \\ of real estate and housing based on recent occupations in São Paulo
}

Luciana Nicolau Ferrara [l]

Talita Anzei Gonsales [II] Francisco de Assis Comarú [III]

\begin{abstract}
Resumo
0 conceito de espoliação urbana foi formulado nos anos 1970, para explicar as péssimas condições de vida a que estava submetido o trabalhador com baixos salários na industrialização em São Paulo. Nas décadas seguintes, a produção imobiliária ganhou centralidade econômica, gerando crescente valorização nesse setor. Esse processo, somado à condição de renda, impede 0 acesso à moradia pelos pobres e evidencia as contradições inerentes à propriedade privada como solução habitacional. A partir de observações sobre uma ocupação periférica recente e outra na região central, busca-se refletir sobre novas espoliações urbanas, identificando estratégias de luta pelo direito à moradia. Conclui-se que as ocupações coletivas têm potencial de contestar a propriedade privada, e as desigualdades, porém, não estão livres das contradições por elas engendradas.
\end{abstract}

Palavras-chave: habitação popular; ocupações urbanas; espoliação urbana; conflitos urbanos; valorização imobiliária.

\begin{abstract}
The concept of urban dispossession was formulated in the 1970s to explain the poor living conditions of workers during industrialization in São Paulo. In the following decades, real estate became central to economy, which made house prices rise. This process, together with the condition of low income, restricts the access of the poor to housing and reveals the contradictions inherent in private property as a housing solution. Based on observations of a recent occupation in the periphery and another one in the central region of the city, new forms of urban dispossession are discussed in the article, identifying strategies to struggle for the right to housing. It is concluded that collective occupations have potential for challenging private property and inequalities; however, they are not free from the contradictions they engender.
\end{abstract}

Keywords: social housing; urban occupations; urban dispossession; urban conflicts; increasing house prices. 


\section{Introdução}

A precariedade urbana e da moradia apresenta uma multiplicidade de dimensões, contradições e conflitos relacionados à propriedade imobiliária que estão distantes de serem tratados pelas políticas públicas ou de serem reconhecidos socialmente, de forma crítica mais ampla. Com um olhar exploratório a partir de aferições sobre dinâmicas socioterritoriais de ocupações recentes para fins de moradia, no centro e na periferia do município de São Paulo, são tensionados os conceitos de espoliação urbana e insurgência. Dentre essas múltiplas dimensões, a análise enfatiza, principalmente, a relação entre produção e valorização imobiliária e suas consequências na produção da cidade; bem como as contradições inerentes à propriedade privada individual como solução predominante para a moradia social no Brasil. Em um contexto de reprodução de desigualdades socioterritoriais e de novas formas de espoliação urbana, quais são os espaços ${ }^{1}$ (materiais e sociais) das dinâmicas reivindicativas ou insurgentes em relação à solução da moradia popular?

Esse debate pode ser realizado se recuperado o conceito de espoliação urbana à luz das dinâmicas contemporâneas de produção do espaço urbano. As condições de vida dos pobres na cidade foram compreendidas, pelos estudos urbanos dos anos 1970 e 1980, como parte do processo de urbanização desigual, movido pela industrialização desde meados de 1940. 0 conceito de espoliação urbana (Kowarick, 1979) explicitou a dimensão a que chegava a exploração do cidadão e do trabalhador industrial que, para viver com baixo ou nenhum salário, precisava autoconstruir sua casa (e seu bairro) nos finais de semana e de seguir um cotidiano de deslocamentos desgastantes, de dificuldade de acesso aos serviços públicos e de longas jornadas de trabalho. 0 rebaixamento dos salários, que não garantia a reprodução da família, permitia maiores lucros do setor industrial (Maricato, 1982) e gerava a precariedade urbana na metrópole considerada "locomotiva do Brasil", no período do chamado "milagre econômico". A industrialização ocorreu sobre uma estruturação fundiária concentrada, com raízes no século XIX, na qual a mercantilização da terra, no campo e na cidade, produziu desigualdades socioespaciais que se reproduzem e se atualizam, em diferentes contextos econômicos.

Os loteamentos populares sem infraestrutura, conformando a expansão periférica metropolitana, somaram-se aos cortiços e ocupações de favelas. A produção doméstica da moradia ${ }^{2}$ (ou autoconstrução) deu-se em sua maior parte como meio de a população trabalhadora buscar solução individual e alternativa de abrigo em franjas, interstícios da metrópole, criando territórios ${ }^{3}$ populares. Contudo, a sobrevivência na cidade implicou a necessária organização social para a reivindicação de melhorias urbanas em loteamentos, a luta por saneamento nas favelas e outras formas de mobilização ante o poder público. Parte dos novos assentamentos populares ocorreu a partir da organização da população dos sem-teto em ocupações organizadas coletivamente, tanto de glebas ociosas na periferia, como por exemplo, a fazenda da Juta na zona Leste de São Paulo nos anos 1980, ou a ocupação da rua do Carmo no distrito da Sé nos anos 1990 (Barbosa, 2014).

Além do contexto da urbanização industrial, desde 1970, o setor da construção civil e 
a atividade imobiliária em São Paulo apresentaram um crescimento expressivo, ampliando a produção em bairros do centro expandido e, nas décadas seguintes, avançaram em novas fronteiras, chegando, nas últimas décadas, a transformar áreas da periferia consolidada da metrópole. Ao longo desse processo, a valorização imobiliária e o aumento do preço dos aluguéis foram constantes, com raros momentos de estabilização. Verificaram-se, também, a expansão e o adensamento dos assentamentos precários - como cortiços, favelas, loteamentos irregulares - e, desde meados dos anos 1990, o aumento das ocupações de edifícios em áreas centrais e infraestruturadas, cujos distritos apresentavam uma grande quantidade de imóveis vacantes ou abandonados. A reprodução das ocupações precárias é um processo combinado à produção e à valorização imobiliária em outros setores da metrópole, assim como ao processo de abandono dos centros históricos, por parte das elites (Teixeira et al., 2005).

Como explicitado por Maricato (1988), a moradia é um bem especial e precisa ser tratada de forma específica no âmbito da regulação urbana e das políticas públicas e fundiárias. Primeiramente, porque se constitui como o item mais caro do custo de vida familiar. Além disso, a moradia está ligada a terra e, portanto, sujeita às condicionantes da localização, aos investimentos públicos e privados realizados no entorno. Pelo seu elevado custo, a moradia demanda financiamento público, e seu relativamente longo processo de produção imobiliza o capital durante sua construção. Trata-se de um item passível de incorporar intensa valorização, mesmo nos casos em que o proprietário não realize nenhum trabalho, investimento ou melhoria. Ou seja, o título de propriedade garante, ao proprietário, a obtenção de renda fundiária. Dois imóveis idênticos em localizações diferentes podem ter seus preços de mercado completamente distintos em função da localização e dos investimentos públicos realizados na cidade.

Hoje, para além do conceito da espoliação urbana formulado por Kowarick (1979), ainda válido e atual, é necessário também considerar os processos contemporâneos que inviabilizam o acesso a terra urbanizada ou a um imóvel bem localizado por parte da população de baixa renda, em um momento de transformação em que a urbanização já não é mais predominantemente produzida sob impulsos da expansão industrial. Nesse sentido, a espoliação imobiliária e financeira, conforme formulado por Pereira (2016), evidencia que, para além da condição de exploração do trabalho, grande parte da população urbana não acessa a moradia digna devido a um processo crescente de valorização imobiliária - processo complexo que explica a crise urbana e o problema da moradia.

Um quadro geral da dimensão sobre os assentamentos populares pode ser verificado segundo dados do Plano Local de Habitação de São Paulo de 2016, ${ }^{4}$ que estimou 445.112 domicílios em favelas, 385.080 em loteamentos irregulares, aproximadamente 80.389 domicílios em cortiços (segundo dados do Plano Municipal de Habitação de 2009), além de 15.905 pessoas em situação de rua (Prefeitura de São Paulo, 2016). Em 2018, a partir de levantamento da prefeitura com participação de assessores dos movimentos sociais, identificaram-se em bairros consolidados, 51 edifícios ocupados onde moravam cerca de 3.500 famílias (Prefeitura 
de São Paulo, 2018). Devido à dinâmica de reprodução do espaço, observam-se que novas ocupações, organizadas ou não, continuam ocorrendo permanentemente. Ao mesmo tempo, surgem diferentes modalidades de ocupação e formação de novos assentamentos populares da classe trabalhadora, com características socioeconômicas, culturais, comunitárias e políticas próprias, no que se refere à possibilidades e estratégias de organização coletiva.

Considerando esse contexto e a dominância do setor imobiliário na configuração da metrópole (Pereira, 2016), este artigo busca refletir sobre conflitos e contradições relativos à propriedade privada imobiliária (fundiária e edificação) bem como às possibilidades de insurgência ou superação desse imperativo, tendo como base aferições empíricas de duas ocupações urbanas recentes no município de São Paulo. A primeira refere-se à uma ocupação recente situada no distrito Grajaú, extremo sul do município, em área de proteção dos mananciais, muito próximo à represa Billings, a Ocupação Gaivotas. E a segunda refere-se a um prédio ocupado há mais de oito anos na avenida São João, n. 588, distrito da Sé, centro de São Paulo, próximo às estações de metrô Anhangabaú e República. Trata-se de duas situações bastante distintas quanto à história, à origem das famílias, ao processo de organização social e espacial, mas que têm em comum o problema estrutural do acesso a terra urbanizada e aos imóveis bem localizados.

Para realizar essa reflexão, além desta introdução, o artigo estrutura-se recuperando uma abordagem teórica sobre os fundamentos da propriedade privada da terra, articulando-a à questão da moradia no atual contexto da urbanização, mobilizando, também, a noção de justiça social. Em seguida, são destacadas situações que iluminam e exemplificam aspectos contraditórios em relação à propriedade privada que derivam da luta da moradia, ao mesmo tempo que se busca identificar "brechas" e movimentos insurgentes nessas ocupações, que são contestatórios e indicam caminhos para novas práticas urbanas.

As noções de cidadania insurgente (Holston e Carina, 2013), planejamento insurgente e planejamento radical (Miraftab, 2009), planejamento conflitual (Vainer et al., 2013) têm sido mobilizadas em diferentes realidades urbanas no sentido de buscar compreender práticas e processos que explicitam as desigualdades sociais vis-à-vis melhores condições de igualdade e justiça. Miraftab (2009) analisa em que medida a cidadania é alcançada pelos pobres no contexto Sul global, ${ }_{1}^{5}$ considerando o avanço das políticas neoliberais que reduzem a ação do Estado em favor de capitais (financeiros) e interesses privados, reduzindo ou retirando direitos sociais, particularmente a partir da década de 1990. Articulado a esses processos, o neoliberalismo, nos últimos anos, tem viabilizado a criação de espaços formais de governança e participação com papel de estabilizar a relação entre Estado e cidadãos, sustentando uma narrativa inclusiva, o que torna esses espaços locais de legitimação do poder instituído, no bojo da produção e reprodução dos "ambientes de negócios", de um lado, e da "exclusão socioespacial", de outro. Assim, a insurgência é entendida, nesta análise, como "práticas contra-hegemônicas, que expõem e perturbam relações normalizadas de dominação" (ibid., p. 34). Essas práticas podem ser efêmeras ou duradouras, envolverem participações em espaços formais ou manifestações 
espontâneas (inventadas, nos termos de Miraftab), utilizarem-se de procedimentos jurídicos ou de outras práticas informais de oposição. Trata-se de movimentos de organização coletiva que "desestabilizam a ordem" e que atuam contra processos de expulsão de terras, remoções involuntárias e outras formas de retirar o trabalhador de seu lugar de moradia para dar espaço a projetos e intervenções urbanas de diferentes portes.

Para Vainer et al. (2013), no Rio de Janeiro, a luta da comunidade da vila Autódromo contra as remoções, que eram justificadas pelas intervenções dos Jogos Olímpicos, aproxima-se das considerações de Miraftab sobre práticas radicais e insurgentes. A contraposição aos projetos propostos pela prefeitura mobilizou a articulação de diferentes sujeitos, dentre eles, a universidade e a Defensoria Pública, na construção de um plano alternativo que demonstrava a viabilidade da permanência dos moradores no local. Os autores denominaram esse processo planejamento conflitual. Apesar das resistências, não necessariamente, o resultado das insurgências ou transgressões resultou na conquista de direitos, embora, no mais das vezes, ampliou a visibilidade e contradições dos processos, fortaleceu a solidariedade, despertou indignação e semeou possibilidades de novos aprendizados coletivos e individuais no seio dos processos de lutas urbanas por dignidade, moradia e justiça territorial.

A partir das distintas situações de centro e periferia da metrópole, as análises dos conflitos e as contradições serão realizadas de modo exploratório, à luz de uma abordagem atualizada do conceito de espoliação urbana (Kowarick, 1979) associada à espoliação imobiliária (Pereira, 2016) e, também, em diálogo com a literatura recente sobre práticas insurgentes. A abordagem metodológica adotada tem como pontos de partida a observação e o levantamento de dados empíricos a partir de projetos de extensão e pesquisa em andamento nos dois contextos urbanos, desde $2018 .{ }^{6}$

\section{A propriedade privada da terra urbana, a moradia e os conflitos com as noções de justiça social e insurgência}

0 debate sobre a moradia tem como um dos fundamentos a compreensão do papel central que a propriedade privada da terra desempenha no processo de urbanização capitalista e das consequências da valorização crescente dos preços dos imóveis como resultado da atividade imobiliária e da construção coletiva das infraestruturas e dos espaços da cidade. A terra possui um duplo monopólio, ou seja, a terra é local de exploração e extração para a produção industrial ou também para construção, 0 que garante, ao industrial (ou ao construtor), a extração de lucros suplementares na forma de renda. Ao mesmo tempo, a terra é monopólio privado, o que confere, ao seu proprietário grande, poder de extrair renda a partir da apropriação privada da produção social do espaço urbano. Segundo Marx, "a propriedade fundiária cobra seu tributo nos dois domínios" (Marx, 1971, p. 888). Nesse sentido, a terra é apropriada em parcelas, privadamente, conferindo, ao proprietário, o direito de utilizá-la e explorá-la, ao mesmo tempo que parte significativa da valorização apropriada privadamente deriva de uma construção coletiva. 
No Brasil, diversos autores demonstraram que uma das origens que estruturam a desigualdade socioespacial é o processo histórico que impossibilitou trabalhadores e moradores pobres "não proprietários" de se tornarem proprietários (Kowarick, 1979; Maricato, 1982; Bonduki, 1998). A concentração da terra em latifúndio não foi transformada por processos de reforma agrária e urbana no País. Além disso, no sistema capitalista - particularmente no caso brasileiro -, a cidadania está vinculada à propriedade, o que perpetua a desigualdade necessária à manutenção do sistema. Em outros termos, no dizer de Oliveira (2013, p. 14), "a âncora da cidadania é a propriedade".

Assim, a mercantilização da terra, e por consequência da habitação, e a instrumentalização do espaço pela urbanização capitalista interditam a dimensão humana do morar na cidade com o desejável e necessário acesso aos bens, serviços e infraestrutura (e muito mais) que permitiriam, em parte, a fruição do direito à cidade, como algo que só pode ser concebido como "direito à vida urbana", a cidade como "lugar do encontro, prioridade do valor de uso" (Lefebvre, 2001, p. 118).

No contexto atual, pesquisas têm alertado para o intenso processo de valorização imobiliária que assaltou as cidades brasileiras durante e após o período de investimentos maciços promovidos pelo Governo Federal, por meio das obras de infraestrutura do Programa de Aceleração do Crescimento (PAC), e, em termos imobiliários, principalmente decorrentes do Programa Minha Casa Minha Vida (MCMV). Em que pese a relevância destes e de outros programas sociais que viabilizaram a inclusão de milhões de brasileiros no mundo do consumo de bens e serviços essenciais, com a contribuição histórica de tirar o Brasil do mapa da fome da ONU, esses mesmos investimentos, num quadro de ausência de regulação fundiária adequada nas cidades, contribuíram para um aumento descolado dos preços dos imóveis urbanos em várias cidades. Ao mesmo tempo, o Programa garantiu os ganhos extraídos do processo produtivo decorrentes da construção civil.

De acordo com dados da Fipezap, ${ }^{7}$ a partir de 2008, ocorre uma valorização do preço dos imóveis na cidade de São Paulo - que supera em muito os índices inflacionários, como o Índice Geral de Preços do Mercado (IGP-M). Entre 2008 e 2018, há uma variação de $231 \%$ dos preços dos imóveis, enquanto, no mesmo período, o IGP-M varia 74,3\%. Mais do que apenas o locus dos negócios, a cidade tornou-se um "negócio em si", e a moradia é capturada como uma das principais e mais rentáveis mercadorias para investidores ávidos por rentabilidade e baixos riscos.

No centro de São Paulo, por exemplo, são lançados apartamentos compactos "studios ou lofts", 8 para utilizar nomenclaturas do mercado, cujo valor por metro quadrado chega a 18 mil reais ou mais. Certamente isso eleva os preços de aluguel dos imóveis da região e, consequentemente, impacta as condições de sobrevivência do trabalhador "não proprietário" de baixa renda que necessita pagar aluguel tanto na região central, quanto em bairros intermediários ou periféricos. Além disso, recentemente outros fenômenos urbanos, como a difusão dos aluguéis na plataforma Airbnb, tem contribuído para impactar ainda mais os preços dos imóveis e aluguéis em distritos consolidados da metrópole (Zillig, 2019). 
Além do custo da moradia, que impõe que a população pobre habite em condições precárias, a vida na cidade cobra um custo elevado do ponto de vista do acesso aos outros serviços e infraestruturas essenciais, como mobilidade e transporte, alimentação, educação, saúde, lazer e cultura, principalmente devido à progressiva tendência de esses serviços serem privatizados. É fato que ocorreu, nas últimas décadas, um aumento da cobertura dos serviços urbanos e maior acesso aos domicílios próprios, como mostra Marques (2015) a partir de dados do Censo 1950-2010. No entanto, as desigualdades mantiveram-se, em termos tanto de qualidade como de distribuição regional dos serviços (com piores índices nas regiões Norte e Nordeste). Além disso, no contexto de dominância financeira, Shimbo (2018) ilustra que a população de baixa e média renda apresenta altas taxas de endividamento, devido aos financiamentos habitacionais firmados nos últimos anos, além do uso do cartão de crédito (motivo principal).

Segundo Kohara (2013), os moradores dos cortiços pagam um aluguel extremamente elevado para residir (precariamente) na região central - arcando, relativamente, com um dos valores mais altos de aluguel por metro quadrado de toda a cidade. Parte dos moradores considera que residir no centro traz algumas vantagens importantes, entre elas, o menor tempo e o menor custo no deslocamento diário entre moradia e trabalho. Para eles, o valor da locação da moradia nos cortiços chega a custar, por metro quadrado, três vezes mais que uma moradia adequada no mesmo bairro. Quando comparado com os valores de aluguéis nos cortiços pagos pelos estrangeiros, essa relação supera a cinco vezes. Essa situação explicita que o grau de exploração pelo mercado está associado ao grau de vulnerabilidade da família ${ }^{9}$ (ibid.).

Assim, nota-se que a classe trabalhadora, por insuficiência salarial e por conta das condições de produção e reprodução da moradia e da cidade, habita em condições precárias que se diversificam em cortiços e ocupações de edifícios mais presentes na região central, mas também em favelas, loteamentos populares, concentrados na periferia geográfica da metrópole, em que o adensamento populacional e construtivo é agravado pelo fato de se residir em bairros distantes dos centros de serviços, das ofertas de postos de trabalho e de redes de infraestrutura e urbanidade. Com a reprodução de precariedades em praticamente todo o território da metrópole, a autoconstrução nas periferias foi (e continua sendo) a arquitetura possível (Maricato, 1982).

A crise habitacional contemporânea tem ganhado contornos de emergência social e humanitária. Lideranças de ocupações do centro de São Paulo têm reiterado que a família de baixa renda "se paga aluguel não consegue comer ou, se come, não consegue pagar o aluguel". Apesar disso, após 2015, com o agravamento da crise política, social e econômica que atinge o País, milhares de famílias têm sido despejadas, reintegradas e removidas de suas residências em função da incapacidade de pagamento de aluguel, de grandes projetos e obras de desenvolvimento urbano e reintegrações de posse proferidas pelo judiciário em favor de proprietários que, em muitos casos, não têm dado função social aos imóveis, deixando-os abandonados e sem manutenção. Imóveis 
abandonados podem (e tendem a) cumprir uma função especulativa, como se sabe (Rolnik et al., 2017).

As ocupações realizadas pelos sem-teto na região central da cidade, por exemplo, cumprem objetivos diversos: pressionar o poder público por políticas de habitação na região central da cidade; ampliar a visibilidade do problema da moradia; viabilizar abrigo (mesmo que provisório) para inúmeras famílias da ocupação em questão; e criar perspectiva de diálogo para um eventual projeto habitacional no prédio em questão, a partir de regularização fundiária e da reforma do edifício. Barbosa (2014) estima que, entre 1994 e 2014, os movimentos de moradia organizaram cerca de 200 ocupações de edifícios abandonados no centro de São Paulo. Para os movimentos, as ocupações são uma das ferramentas de luta para denunciar os imóveis vazios ou abandonados que não cumprem sua função social. 0 autor, ainda, aponta que a principal questão que inviabiliza a garantia de habitação social em áreas dotadas de infraestrutura é a do acesso à terra.

Além disso, vale salientar que, além das ocupações, outras ferramentas de luta ou de práticas insurgentes são mobilizadas, como a atuação em instâncias de participação popular, a organização de grupos de base, que têm como objetivo a formação política e o entendimento das pessoas como protagonistas e sujeitos de direito, a participação de ações diretas, como a organização e participação de atos públicos, dentre outras estratégias. Com o passar do tempo, as ocupações, que surgiram como meios de reivindicação do direito à habitação, provendo temporariamente a moradia, foram resistindo aos processos de reintegração de posse, tornando-se uma alternativa para as famílias.
Em levantamento recente realizado pela Prefeitura São Paulo, foram identificados 51 edifícios ocupados nos diversos distritos da região central e centro expandido, incluindo-se: Sé, República, Mooca, Vila Prudente, Lapa, Pinheiros, Brás, Bela Vista, Butantã, entre outros. Nesse conjunto, há aproximadamente 3.500 famílias, totalizando 10.562 pessoas; e, em $86 \%$ dos edifícios, há pessoas idosas morando. 0 relatório mostra que 35 ocupações são de propriedade privada e 16 de propriedade pública, $57 \%$ estão vinculadas a movimentos de moradia e $52 \%$ possuem débitos com a prefeitura referentes aos impostos municipais, totalizando um valor de $\mathrm{R} \$ 21.750 .751,59$. Além disso, o relatório mostra também que 11 ocupações têm algum tipo de intervenção proposta e 5 possuem previsão de projetos (Prefeitura de São Paulo, 2018). Cabe destacar que se trata de um fenômeno consideravelmente dinâmico, uma vez que as ocupações surgem e são removidas quase que diariamente, sejam elas organizadas por movimentos ou não. Sendo assim, é difícil precisar o número exato de ocupações existentes em São Paulo.

Em áreas distantes dos bairros centrais, nas bordas da mancha metropolitana, inclusive sobre áreas ambientalmente protegidas, o crescimento populacional tem ocorrido em áreas já ocupadas, gerando o aumento de densidade populacional e construtiva dos assentamentos existentes. Na Área de Recuperação e Proteção de Mananciais (APRM), tanto ao sul, como ao norte de São Paulo, a ocupação ou venda ilegal de terrenos tem promovido o "preenchimento" de alguns "vazios" urbanos, dando continuidade à expansão da mancha urbana sem a provisão de infraestruturas. Como mostram Pasternak e D’0ttaviano (2016, p. 96), com base 
nos dados do Censo IBGE 2010, na década de 2000, as favelas cresceram mais no município de São Paulo do que em outros municípios da metrópole, e o crescimento populacional municipal e da população das favelas ocorreu mais intensamente na periferia da cidade (anel exterior e periférico, que ganharam 123 mil e 239 mil pessoas, respectivamente) se comparado ao chamado anel central.

Diante desse quadro de injustiça social e ambiental, é evidente que as formas de luta por moradia se tornam urgentes e legítimas, porque se situam no campo do estado de necessidade humana e visam a se contrapor à desigualdade socioespacial, assim como, a promover melhores condições de vida para a população de baixa renda na cidade. Essa perspectiva convive com um processo de valorização imobiliária que reproduz as condições de desigualdade; dificulta a aquisição de terrenos e imóveis pelo poder público e pela população em geral; e, ao mesmo tempo, incentiva a continuidade da expansão precária, em todo o território. Contudo, a solução do problema por parte do poder público tem sido reiterar o financiamento para a aquisição de uma propriedade privada como saída para a crise urbana, sem que se aprofunde a crítica a esse modelo, que apresenta diversas contradições, inclusive, para os grupos organizados e os movimentos sociais, e sem que se altere ou se contraponha ao processo geral de valorização imobiliária.

No sentido de formulações contra-hegemônicas, a identificação de práticas e experiências que rompem com os modelos instituídos, ainda que não constituam transformações estruturais, podem indicar caminhos e novas formas de reagir e associar o problema da moradia como parte de uma luta social mais ampla. Autores têm produzido conhecimento com os movimentos urbanos e identificado algumas práticas, que podem resultar em processos de planejamento insurgente (Miraftab, 2009) ou de planejamento conflitual (Vainer et al., 2013), que tem como ponto de partida os processos de resistências sociais contra grandes projetos urbanos, remoções forçadas ou, nos casos em foco, processos de ocupação de imóveis e terrenos, indicando também uma luta dos moradores pela sua permanência no espaço e ao longo do tempo.

Nesse contexto, cabe mencionar que a associação entre Estado e mercado, garantindo interesses privados em detrimento do interesse público e social, tem dominado grande parte das correlações de forças e orientado a política urbana, seja no planejamento e no desenho dos instrumentos (Rufino, 2018), seja na provisão habitacional (Shimbo, 2012). Portanto, há uma desigualdade de poder econômico e político em relação aos agentes produtores do espaço que estão implicados nas tensões sobre a propriedade imobiliária e na disputa por localização urbana, fazendo com que processos contestatórios e insurgentes sejam coibidos com repressão e violência.

Harvey (1980) chama-nos a atenção sobre qual a medida que a alocação de recursos em um determinado território afeta as condições de outros territórios, principalmente os investimentos públicos. Para ele, a "necessidade" é analisada como um dos parâmetros de medição da justiça social territorial, enquanto categoria que pertence a uma esfera da consciência humana, e por esse motivo de difícil classificação. 0 autor parte do pressuposto de que, se estamos avaliando as necessidades dos indivíduos ou de grupos específicos, tal fato é reflexo 
da distribuição desigual de benefícios no território, apesar de todos, enquanto cidadãos, em tese, gozarem do mesmo direito (ibid.).

Se a função social da propriedade, tal como estabelecida na Constituição Federal de 1988 e na legislação urbanística, não tem sido atingida por meio de procedimentos institucionais e normativos, a função social da terra, por meio de ocupações, tem se colocado como consequência da espoliação urbana e imobiliária, enquanto uma forma de acessar um espaço de vida na cidade. A partir desse contexto e problematização em escala mais ampla, busca-se refletir sobre a prática de ocupações urbanas em diferentes localizações da metrópole.

\section{Duas situações de ocupação urbana no centro e na periferia: conflitos e contradições}

\section{Ocupação no centro: a experiência e luta da Ocupação São João 588}

A Ocupação São João 588 é resultado de um trabalho coletivo e de organização do movimento popular a partir do qual é possível tanto aprofundar o debate sobre as tensões em torno da propriedade privada, que ora é barreira e ora aparece como solução para o problema da moradia, quanto problematizar de que modo tais tensões constituem insurgências. A ocupação de edifícios resulta do processo de organização prévia, mobilizada por coordenadores de grupos de base que convidam pessoas em situação de dificuldade financeira para se mobilizarem, e ali iniciam discussões sobre organização, direitos, deveres e o processo de luta pela conquista da moradia adequada. De acordo com uma das lideranças do Movimento Sem-Teto e Reforma Urbana (MSTRU), um dos movimentos que atua no município de São Paulo, ele agrega cerca de 1500 pessoas, divididas em 30 grupos de base espalhados pela cidade. Destes, $30 \%$ dos integrantes ${ }^{10}$ manifestaram interesse em ocupar outros imóveis abandonados por conta das dificuldades em pagar o aluguel em suas residências de origem.

0 antigo Hotel Columbia Palace foi ocupado pelo MSTRU, em 2010, após permanecer abandonado por cerca de 30 anos, dando origem à Ocupação São João 588. Localizado na região central de São Paulo, próximo a uma das esquinas mais famosas da cidade, o prédio passou, enfim, a cumprir função social, servindo de moradia a tantas famílias que se encontravam desamparadas na situação de sem-teto.

A entrada no edifício é um momento crítico e de resistência, ante a possibilidade de reintegração de posse imediata. É possível dizer que é uma ação transgressora, considerando a visibilidade dos imóveis em área central, mas, principalmente, porque o direito à propriedade privada se sobrepõe frequentemente ao direito à moradia digna no Brasil, na interpretação de alguns operadores do direito e do Estado brasileiro. Além disso, os dias iniciais demandam extrema organização e autogestão dos ocupantes para tornar o espaço habitável, realizar limpeza, retirada de entulho, ligação de instalações de água e eletricidade, entre outros reparos emergenciais necessários para o abrigo, mesmo que provisório, de dezenas ou centenas de famílias. A Ocupação São João 588 é um dos casos em que essa organização comunitária se manteve no tempo, com formas inventivas de convivência, ou "imaginativas", nos termos de Miraftab (2009). 
Figura 1 - Ocupação São João 588

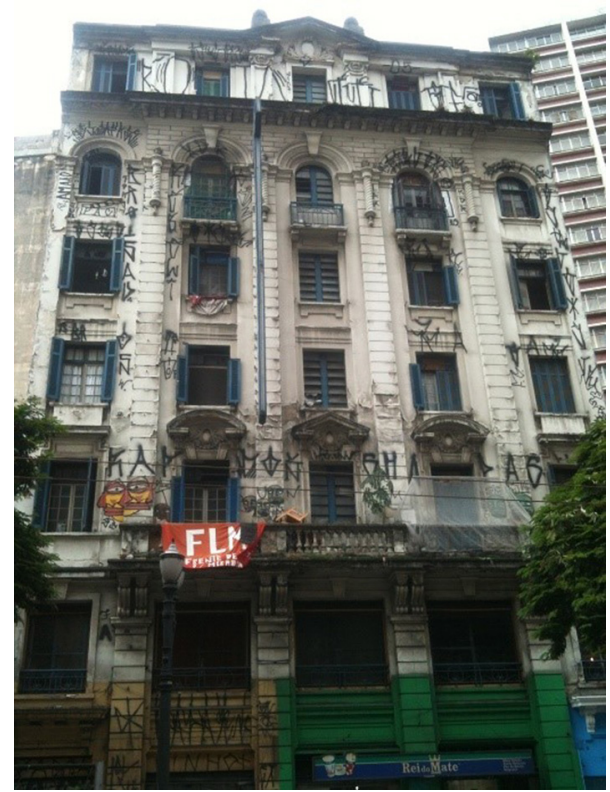

Fonte: Francisco de Assis Comarú, março de 2014.

Em 2018, a ocupação abrigava cerca de 90 famílias, totalizando aproximadamente 300 pessoas que seguiam resistindo às diversas tentativas de reintegração de posse do edifício nos últimos anos. Tratava-se, portanto, de uma situação de permanente tensão adiante da instabilidade da posse do edifício.

Apesar disso, os diversos relatos de moradores expressam trajetórias de pessoas que conseguiram estruturar suas vidas por residir numa ocupação. Alguns deles chegaram a concluir curso superior, seja pela proximidade a um grande leque de oportunidades urbanas, seja pela rede de apoio e solidariedade que vai se constituindo ao longo do tempo. Segundo relatos de lideranças do movimento, as mulheres compõem o maior número de pessoas que buscaram um curso superior ao longo desses anos de ocupação.

Após oito anos no edifício, destaca-se a capacidade de organização comunitária, e grande parte das atividades e responsabilidades é compartilhada entre os moradores. Em cada andar há um moderador que organiza as responsabilidades de limpar e zelar pelos espaços coletivos. Semanalmente, uma família é responsável pelas atividades, com a prática da alternância. 0 mesmo acontece com a limpeza do salão da ocupação, espaço no qual são realizadas assembleias, reuniões e atividades culturais. Segundo uma das lideranças do MSTRU, após tantos anos de ocupação, percebe-se que as relações se individualizam, por isso, no seu entendimento, o esforço de manter 
as atividades enquanto uma responsabilidade coletiva reforça o caráter comunitário da presença e ação dos moradores no espaço comum. Ela relata com orgulho que faz questão de que todas as famílias participem das reuniões junto ao poder público e ao judiciário, no intuito de que todos conheçam a complexidade dessas relações e dificuldade das negociações.

Dentre as regras de convivência do prédio, que são pactuadas coletivamente, algumas são inegociáveis: é terminantemente proibido o tráfico de drogas e práticas que caracterizem o contrabando, assim como não é tolerável a prática de violência doméstica. Além disso, é obrigatório que crianças e adolescentes frequentem a escola. As lideranças alertam que armas de fogo não são bem-vindas nem toleradas dentro da ocupação.

Um grupo composto majoritariamente por jovens é responsável pela programação cultural da ocupação que, há tempos, abre suas portas para oferecer diversas atividades mensais para a comunidade. As paredes do salão que abrigam as atividades são cobertas por grafites, quadros e fotos que narram o cotidiano dos moradores da ocupação, repletas de referências da resistência e da insurgência.

Ainda que a ocupação resulte em diversos benefícios para a cidade, como a provisão de moradia para famílias de baixa renda, a reforma e manutenção do prédio que antes apresentava riscos para seus vizinhos e o aumento do número de pessoas que circulam pela região, contribuindo para um espaço mais seguro do ponto de vista público, a Ocupação São João 588 já sofreu oito tentativas de reintegração de posse, sem que uma alternativa habitacional fosse apresentada para as famílias que ocupam o prédio.
Segundo Barbosa (2014), as lutas pela moradia na região central, em particular no caso das ocupações de prédios abandonados pelos proprietários e ocupados pelos movimentos de moradia, levam a um processo de aprendizado e transformação profunda das experiências individuais e coletivas daqueles que partilham o cotidiano na ocupação. Para o autor, esses processos despertam uma pedagogia do confronto, proporcionada pela experiência de viver em um espaço de transgressão (Earle, 2012) e de cooperação. Isso não é pouco, numa sociedade que cultiva valores capitalistas, de individualidade, de meritocracia e de solução individual e privada da questão da moradia. Lideranças costumam dizer que aqueles que pisam a primeira vez em uma ocupação nunca saem exatamente como entraram. Transformam-se, em termos de compreender outras dimensões da luta pela moradia, da luta pelo direito à cidade e da construção de sociedades mais justas.

Obviamente que a realidade cotidiana não pode, nem deve, ser romantizada. $A$ organização coletiva apresenta um grande potencial de superar diversas ausências e necessidades e, ao mesmo tempo, torna a convivência mais intensa e, em diversos momentos, conflituosa. Além disso, todos os que residem numa ocupação organizada por um movimento de moradia sabem (ou deveriam saber) que não têm sua moradia definitiva garantida, que podem ter que deixar o prédio a qualquer momento por força de uma reintegração de posse que pode ser muito violenta. Sabem, também, que o sucesso do processo de luta para a conquista da moradia depende de união, organização, além de parcerias e apoios de assessoria jurídica, assessoria técnica, grupos de 
universidades, entre outros atores do campo urbano progressista.

Outro aspecto que ilustra como a formalização ou regularização da moradia tem implicações em outras esferas da vida cotidiana refere-se às tentativas de regularizar a ligação de água junto à concessionária prestadora de serviços, pois, segundo os moradores, isso resolveria a comprovação de endereço, sem o qual várias questões burocráticas e da vida cotidiana ficam dificultadas, principalmente aquelas associadas à procura de trabalho ou emprego. Além disso, o endereço de uma moradia considerada "regular" amplia a própria percepção de inclusão na sociedade e nas instituições no capitalismo. Também se destacam as falas constantes dos moradores quanto à necessidade de regularizar a situação, reiterando que podem pagar pelo serviço de saneamento - ainda que o contexto de baixíssima renda justifique um acesso subsidiado ao sistema público e ao bem coletivo que é a água.

Se, "da porta para dentro", esse edifício é sinônimo de organização, trabalho coletivo e resistência, é notável que, mesmo após anos de abandono e acúmulo de dívidas, devido a impostos não pagos, a ocupação tenha despertado o interesse dos proprietários do imóvel. Aqui se denota outro conflito. Para o movimento de moradia, a ocupação constitui-se, além de abrigo, numa estratégia de luta para a conquista de moradia. Por isso, é considerada, por muitos, uma situação transitória. Contudo, o equacionamento das reivindicações, seja recuperando o edifício ocupado, transformando-o em moradia definitiva, seja a obtenção de moradia em outro local, demanda alguns anos. Durante esse tempo, a judicialização do processo, os pedidos de reintegração de posse e a atuação do poder público diante do conflito, algumas vezes, abre espaço para negociações com os proprietários, muitas vezes associadas à possibilidade de desapropriação do prédio. Ao longo desse processo, a negociação em relação aos valores pode ser delicada, e no caso da Ocupação São João 588 , moradores relataram que, após a prefeitura publicar o decreto de interesse social (DIS), 0 proprietário aumentou o valor que vinha sendo negociado para a compra do prédio.

Situação semelhante ocorreu com a conhecida Ocupação Mauá, cujo valor de referência para desapropriação do edifício passou, em alguns poucos anos, de cerca de 11 milhões de reais em 2013, quando a prefeitura publicou um decreto declarando a ocupação como uma área de interesse social, depositando o valor em 2014, para que o prédio fosse desapropriado, para cerca de 25 milhões de reais. Esse montante resultou de uma avaliação de um perito designado pela justiça que sequer entrou no prédio para realizar o cálculo. Cabe destacar que as dívidas com IPTU do proprietário somavam mais de 5 milhões de reais, e o valor negociado foi de 20 milhões de reais, em 2017, momento em que a desapropriação foi finalizada. Contraditoriamente, a forma como as ocupações são entendidas pelo poder público e pelo judiciário acaba por gerar mais ganhos aos proprietários de imóveis, inclusive aqueles que fecharam e abandonaram o prédio por décadas e que possuem dívidas com o poder público.

Casos como estes evidenciam que a defesa do direito de propriedade individual é considerada inabalável, mesmo adiante da condição social de inúmeras famílias que, se fossem prioridades para o poder público e judiciário, receberiam outro tratamento. 
De acordo com Barbosa (2014) em sua pesquisa sobre as lutas dos movimentos de moradia pela conquista da habitação digna na região central de São Paulo, entre 1989 e 2014 foi produzida cerca de 6.300 unidades habitacionais nos distritos centrais do município considerando toda a produção pública realizada com recursos federais, estaduais e municipais. Essa cifra equivale a uma média de 252 unidades de habitação social por ano na região central, muito aquém da demanda para uma metrópole de cerca de 20 milhões de habitantes. A reforma de edifícios em área central, bem como programas de locação social ou outras formas de se promover acesso à moradia digna bem-localizada, que não sejam apenas o financiamento de um imóvel, não são priorizados no atendimento habitacional em São Paulo. 0 fato de o centro ter se tornado recente fronteira de produção e valorização imobiliária também se apresenta como mais um problema para a permanência da população pobre, seja em imóveis ocupados, seja em cortiços ou no aluguel, além de acirrar a disputa desigual por essa localização.

\section{A Ocupação Chácara Gaivotas, Distrito Grajaú}

A ocupação Chácara Gaivotas está localizada no Grajaú, inserida em uma área maior chamada Jardim Gaivotas, no extremo sul de São Paulo, próxima à represa Billings, em área de proteção e recuperação aos mananciais, na qual incide uma série de restrições ambientais. Segundo os moradores, parte da ocupação é de propriedade pública e outra parte é privada, porém, ainda não se sabem exatamente os limites dessas áreas. 0 que se sabe, devido à consulta ao processo de desapropriação da área que está em curso, é que uma família era proprietária da área ocupada e de todo o entorno, uma região extensa que se encontra completamente consolidada e onde ocorrem muitos conflitos relativos à venda ilegal de terrenos.

A Ocupação Gaivotas abriga atualmente cerca de 150 famílias, e, desde meados de 2013, essa mesma área está sendo ocupada pela segunda vez. Na primeira ocasião, em 2007, as famílias sofreram uma violenta remoção, quando a ocupação tinha cerca de um ano. Essa remoção foi realizada pela fiscalização Defesa das Águas, motivada por possíveis intervenções na área pelo Programa Mananciais (ações de saneamento de urbanização). Moradores relatam que o episódio foi operacionalizado pela Guarda Civil Municipal, que destruiu os madeirites que compunham suas casas, inutilizando o material, de modo a impedir um eventual reaproveitamento. 0 projeto que motivou a remoção, por sua vez, não foi realizado após as remoções.

Uma das moradoras conta que, após a remoção de 2007, ficou abrigada provisoriamente em um campo de futebol próximo da região e, em seguida, recebeu auxílio-moradia da prefeitura por seis anos, quando cortaram seu benefício sem aviso prévio e sem debater sobre possíveis alternativas para o atendimento habitacional dela e de outras famílias. A única alternativa que lhe restou foi a reocupação da área, em 2013. Diante da impossibilidade de compra de uma moradia no mercado e com dificuldades para acessar o mercado de aluguéis, desde então, outras famílias foram retornando para o Gaivotas, e a área foi se adensando, com destaque para o período entre junho de 2017 e abril de 2018, quando 
Figura 2 - Ocupação Gaivotas, no extremo sul de São Paulo

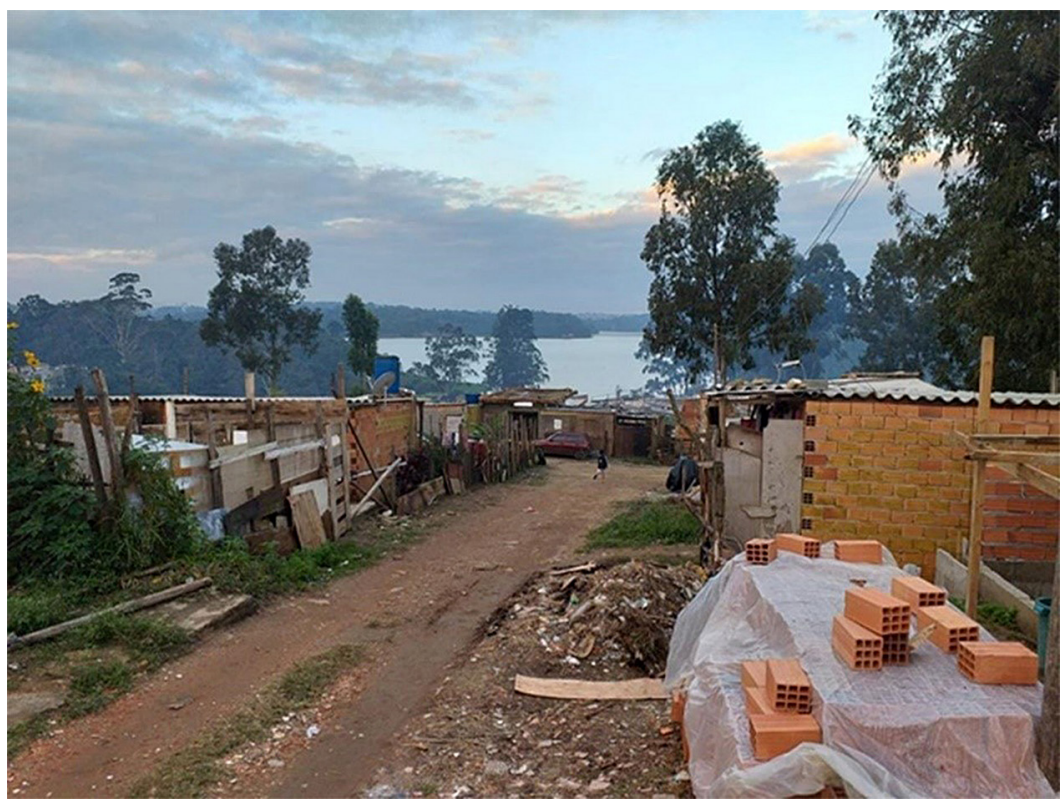

Fonte: Francisco de Assis Comarú, junho de 2019.

houve maior construção de casas. Moradores contam que a busca por espaços na ocupação é cotidiana e motivada pela dificuldade de as famílias arcarem com custos de aluguel, mesmo em outras regiões do Grajaú.

Outra moradora com quatro filhos também removida em 2007 tinha pagado cinco mil reais pelo terreno na época e, após a remoção, alugou uma casa. Porém, após perder o emprego, não conseguir mais pagar o aluguel, teve que ficar na rua alguns dias, quando uma antiga vizinha soube e cedeu parte da sua casa no Gaivotas para abrigá-la. Hoje ela está numa casa cedida na ocupação, vivendo apenas com os recursos que recebe do Bolsa-Família, uma vez que ainda não conseguiu encontrar um emprego. Questiona sobre a situação fundiária da ocupação, ela disse: "se a área é da Prefeitura, então é nossa também e nós podemos morar.
O terreno estava parado e nós estávamos na rua, não tem por que [...]". Essas trajetórias individuais explicitam as dificuldades cotidianas da população que vive em uma das localidades mais pobres da cidade.

Os atuais moradores e lideranças da área reafirmam sua diferença em relação aos assentamentos do entorno, no sentido de que lá não há compra e venda de terras, mas as famílias organizam-se e dividem o espaço por necessidade. 0 uso do espaço para moradia prevalece ante as possibilidades de mercantilização de lotes, muito comum na periferia de São Paulo. A distribuição das terras se dá com a organização de lotes familiares, bem-delimitados, acompanhando traçado pré-definido das ruas e vislumbrando um possível processo de regularização futura, conforme explicam algumas lideranças locais. Contudo, 
essa organização espacial, estruturada e individualizada contrasta com a organização social incipiente dos moradores. ${ }^{11}$ Não é possível prever até quando a necessidade de moradia será equacionada, principalmente pelo uso e apropriação da terra e não pela venda de pedaços de terreno, nos próximos anos.

A gleba ocupada não possui infraestrutura, e os moradores do Gaivotas enfrentam dificuldades no que diz respeito aos serviços de abastecimento de água, esgotamento sanitário e energia, e dependem da existência de ligações informais às redes públicas, o que gera problemas frequentes de acesso à água em quantidade e qualidade, devido a processos de contaminação a que estão sujeitas as ligações improvisadas naquela região. As ruas que formam a ocupação são de terra batida, tendo seu acesso muitas vezes dificultado nas épocas de chuva. Além disso, a condição construtiva das casas é precária, predominando construções em madeira, lona e materiais improvisados. Mas observa-se, com o passar dos meses, a rápida transformação das moradias em construção de alvenaria, e um número crescente de construções. Há apenas um espaço reservado para a coletividade, que ainda não está construído. Os espaços que abrigam as reuniões de moradores são pequenas igrejas neopentecostais.

Apesar da ocupação localizar-se próxima a equipamentos públicos de ensino e saúde, a condição de estar em área não regularizada e sem endereço formal exclui esses moradores que dependem integralmente dos serviços públicos de acessá-los. As mulheres relatam que a ocupação não é atendida por agentes de saúde, mas pela Unidade Básica de Saúde (USB) Chácara do Sol. Contudo, a UBS não abre prontuário, o que gera diversos problemas de acompanhamento dos tratamentos e de acesso ao sistema.

Moradores relataram também que têm acesso relativamente fácil às linhas de ônibus que conectam a ocupação com os terminais do Grajaú e Jurubatuba, porém, o acesso à região central é bastante difícil, gastando-se até três horas para o trajeto, a depender do horário.

Em comparação com a Ocupação São João 588, que surge de um processo de organização social articulado a um movimento social, no qual o ato de ocupar é transgressor e insurgente, pois constitui um ato político e de reivindicação por moradia bem-localizada, a Ocupação Gaivotas poderia, num primeiro olhar, não ser interpretada como uma ocupação insurgente, dada a sua forma de ocupação menos organizada, mais fragmentada e com organização coletiva incipiente. No entanto, ambas as ocupações surgem como solução possível ao problema da moradia e, de modos distintos, desafiam a propriedade privada individual para dar lugar a centenas de famílias. Tanto os moradores da Ocupação São João, 588 como os do Gaivotas assumem sua condição e buscam dialogar com o poder público municipal, reivindicando direitos e alternativas de melhor qualidade.

De certo modo, pode-se dizer que ocorrem insurgências cotidianas, em cada ocupação de edifício ou terreno, ainda que essa contestação possa resultar em diferentes formas de permanências em condições de precariedade que estão frequentemente atuando sob a instabilidade da posse, gerando conflitos diversos.

Contudo, no caso da ocupação Gaivotas, o fato de estar localizada em área de mananciais, muito próxima à represa Billings, gera 
situações de maior precariedade para as famílias e acirra o conflito em relação à legislação ambiental. 0 que esse caso explicita é que as soluções habitacionais fora de áreas ambientalmente protegidas continuam não sendo suficientes para a população mais pobre, como já vem sendo debatido há muitos anos (Martins, 2005; Ferrara, 2013). Assim, mantêm-se presentes tanto ocupações como essa, como o processo de venda ilegal de terrenos, que constituem mais uma camada de exploração da população de menor renda.

\section{Discussão e considerações finais}

Após a exposição de conteúdos, conceitos e casos, cabem algumas considerações e reflexões finais. Nota-se que o processo de produção e reprodução de precariedades continua vivo e presente em São Paulo. Se, nos anos 1970, o salário do trabalhador industrial não permitia a reprodução da vida e o acesso à moradia adequada, esse processo parece, não apenas ter permanecido, mas, sobretudo, ter se agravado. A produção e a crescente valorização imobiliária têm se mostrado elementos importantes a serem mais bem-compreendidos, configurando o processo de espoliação imobiliária conforme formulado por Pereira (2016), especialmente em relação as suas consequências em uma sociedade urbana que se reproduz sobre desigualdades socioespaciais. Neste artigo, ainda que de modo exploratório, buscamos articular essa dinâmica imobiliária em curso para problematizar seus efeitos, tanto sobre a reprodução do espaço urbano, como sobre o cotidiano de moradores, iluminando situações de duas ocupações em distintas localizações. $A$ população de baixa renda que não tem conseguido acessar moradia digna, também designada de "sem-teto" não é bem-vinda e "não cabe" na cidade regulada e dominada pelo mercado imobiliário. Assim, milhões de famílias são compulsoriamente levadas a residir em favelas, loteamentos periféricos e precários, ocupações e cortiços. As ocupações urbanas aparecem como verdadeiras "válvulas de escape" para o abrigo de muitas famílias que não logram custear o aluguel de uma residência adequada.

Do ponto de vista de uma análise longitudinal no tempo, os casos contemporâneos da região "central", Ocupação São João 588, e da ocupação "periférica", Gaivotas, mostram algumas permanências e algumas mudanças quando se consideram os processos de exploração e espoliação descritos por Kowarick, e os de autoconstrução descritos por Maricato, nos anos 1970 e 1980.

Quando analisados em perspectiva, nota-se, também, que a população residente em ocupações, tanto em área central, como em área periférica, compartilha problemas e precariedades similares, tais como: insegurança na posse, acesso precário e irregular a serviços essenciais de abastecimento de água, coleta e tratamento de esgotos, energia elétrica. Em ambos os casos, os moradores sofrem a privação imposta pela pobreza, por salários muito baixos, o que impõe restrições severas no acesso à vida digna e ao pleno desenvolvimento humano.

Observam-se, no entanto, algumas especificidades lado a lado. As famílias residentes na ocupação periférica Gaivotas convivem sob 
os impactos de uma localização muito desfavorável em relação à proximidade de postos de trabalho, infraestrutura de mobilidade e transportes e equipamentos urbanos de qualidade em áreas de cultura, educação e saúde. Lá, os moradores deparam-se com o problema da ausência de iluminação pública - que certamente atinge mais as mulheres -, além da ausência de pavimentação e sistema de drenagem e manejo de águas pluviais. Já, na Ocupação São João 588, o fato de estar em área central, consolidada e infraestruturada permite uma inserção distinta dos moradores em alternativas de trabalho, acesso a infraestrutura e serviços.

Nas duas situações, os moradores não gozam de condição de segurança na posse. Como consequência, a ameaça de remoção é sempre presente, algo que afeta a saúde mental e psicológica em nível individual e comunitário com inúmeros impactos tangíveis e intangíveis.

Além disso, se, na ocupação da região central, os residentes sofrem a pressão direta e indireta de processos associados ao alto interesse e valorização imobiliária em curso, na ocupação em região periférica, os moradores sofrem a pressão direta e indireta de processos associados aos conflitos ambientais típicos de áreas de proteção dos mananciais. Contudo, no atual contexto, a ausência de recursos e projetos para essa região faz com que a Ocupação Gaivotas praticamente caia no esquecimento do poder público e assim, aparentemente, consolide-se ao longo do tempo.

Em que pesem os esforços de organização, mobilização e lutas dos sem-teto das ocupações centrais e periféricas, notam-se algumas contradições importantes - que nem mesmo a atuação e o atendimento do estado, como já foi verificado em diferentes momentos no passado recente - têm sido capazes de solucionar.

Um contradição central refere-se à luta pela moradia, concebida enquanto direito e também enquanto propriedade individual e privada. Para realizar este debate, também foi problematizado o fundamento da dinâmica imobiliária e do problema do acesso à moradia que é a propriedade privada da terra e do imóvel. No Brasil, a concentração da propriedade constituiu uma condição de desigualdade que se atualiza.

0 acesso a terra enquanto direito, faz com que se entendam as ocupações como processos insurgentes e contestatórios, que mostram o quanto a propriedade privada impõe limites à ampliação da solução habitacional, apesar de significarem um cotidiano de muito trabalho individual e coletivo, apontam formas diferentes de gestão do espaço de morar. Trata-se de práticas insurgentes ou contestatórias, na medida em que a organização e o ato de ocupar coletivamente um imóvel visando ao uso não mercantil do espaço transgridem, ainda que de modo efêmero, o direito à propriedade privada como barreira para a superação desse problema social. Nesse sentido, é possível estabelecer um diálogo com a concepção de Miraftab (2009) de planejamento insurgente, definido transgressor, contra-hegemônico e imaginativo.

A permanência de ocupações organizadas durante tantos anos, que qualifica edifícios inteiros por meio da autoconstrução, reformas e reparos, mostra que a solução habitacional ampliada será possível se enfrentada a concentração imobiliária de imóveis existentes 
e, simultaneamente, torna necessário revisar as práticas das políticas habitacionais.

Ao mesmo tempo, é importante ressaltar que, apesar do caráter flagrante de insurgência, transgressão e radicalidade das ações dos grupos de sem-teto, nota-se que, sob determinadas demandas, as suas ambições circunscrevem-se a atingir patamares bastante convencionais no que tange à propriedade da moradia dentro dos marcos instituídos pelo sistema capitalista e dos valores individuais, privados e pequeno-burgueses. A grande maioria dos debates, reflexões e demandas dos grupos de sem-teto (inclusive aqueles referentes aos grupos mencionados) limita-se a demandar moradia enquanto bem imóvel a ser financiado em moldes de propriedade privada e individual. Um número bastante reduzido de experiências e lideranças tem proposto o debate e lançado o desafio da produção de moradia como bem de propriedade comum, coletiva, comunitária ou pública, ou, ainda, avaliado outras formas de pressionar o poder público por políticas mais diversificadas, que considerem formas de produção da moradia (ou reforma de imóveis existentes) em novas bases.

Mesmo assim, os movimentos de moradia seguem lutando, em alguns casos, com algumas conquistas importantes, com inúmeras derrotas e sofrendo perseguição e criminalização. Isso porque, em uma sociedade tão desigual como a brasileira, mesmo uma pequena inserção dos pobres como pequenos proprietários gera resistências e é vista como ameaça pelos proprietários e agentes imobiliários de maior poder econômico e político, além do preconceito generalizado da sociedade.

Contudo, a concretização do direito à moradia quando equivale exclusivamente ao "sonho da casa própria" reitera a defesa da propriedade, não só para o "novo" pequeno proprietário, mas principalmente porque é funcional para o setor da construção civil e o grande proprietário imobiliário, que extrai ganhos em todos os momentos do processo de urbanização - tanto com a produção de novas unidades habitacionais, como com a extração de rendas fundiárias.

Assim, as formas contestatórias de pensar e viver a cidade ficam subordinadas à racionalidade econômica na propriedade privada e individual do imóvel. Novas formas espoliativas levantam questões a serem enfrentadas pelos movimentos sociais e pelo planejamento insurgente, ou seja, que visa a se contrapor a esse sistema e suas dinâmicas. As diferentes resistências e lutas emergem como possibilidades e manifestações da necessidade humana que precisará ser reconhecida e atendida pela sociedade e pelo Estado por meio das políticas públicas.

A produção de conhecimentos, a reflexão, a construção de espaços de mediação, diálogo e interlocução junto a esses milhões de famílias sem-teto que se movem na construção insurgente de novos territórios, novas relações, novas sociabilidades e economias desempenharão um papel central no processo de construção de cidades democráticas, igualitárias e includentes. 


\section{[I] https://orcid.org/0000-0002-0493-376X}

Universidade Federal do ABC, Centro de Engenharia, Modelagem e Ciências Sociais Aplicadas, Programa de Pós-Graduação em Planejamento e Gestão do Território. Santo André, SP/Brasil. luferrara@gmail.com

\section{[II] https://orcid.org/0000-0002-8921-1335}

Universidade Federal do $A B C$, doutoranda, Programa de Pós-Graduação em Planejamento e Gestão do Território. Santo André, SP/Brasil

talita.anzei@gmail.com

\section{[III] http://orcid.org/0000-0002-1091-2156}

Universidade Federal do ABC, Centro de Engenharia, Modelagem e Ciências Sociais Aplicadas, Programa de Pós-Graduação em Planejamento e Gestão do Território. Santo André, SP/Brasil. francisco.comaru@gmail.com

\section{Notas}

(1) Neste artigo, o termo espaço é mobilizado no sentido formulado por Lefebvre (1974), sendo ao mesmo tempo produto (resultado da urbanização industrial capitalista) e produtor de relações sociais, na medida em que a produção do espaço entra nas relações sociais de produção, principalmente, quando se trata da produção imobiliária. Nesse sentido, o espaço não é vazio, ou apenas um substrato no qual atividades acontecem, mas está implicado nas relações sociais.

(2) Pereira (2005) problematiza o termo verticalização (produto imobiliário) e autoconstrução (forma de produção). Por isso, desenvolve o termo produção doméstica (autoconstrução da casa própria) como uma das formas de produção do espaço, dentre as quais também ocorre a produção por encomenda, estatal e para mercado.

(3) Neste artigo, o termo território é utilizado como construção social ampla, que possui dimensão econômica, política, cultural (e simbólica). O termo relaciona-se com a apropriação social do espaço de vida (Haesbaert, 2004).

(4) O Plano considerou os dados extraídos do Sistema de Informações para Habitação Social na Cidade de São Paulo (Habisp), em abril de 2016 (Prefeitura de São Paulo, 2016).

(5) Miraftab refere-se aos países do hemisfério sul que foram colonizados, como Brasil e África do Sul, nos quais é possível observar, atualmente, os efeitos das políticas neoliberais que, apesar de se pautarem em discursos de inclusão, aprofundaram processos de segregação que, a nosso ver, são mais bem explicados a partir da noção de desigualdade. A crítica da autora aponta para a necessidade de superar as heranças coloniais e revisar radicalmente a prática do planejamento participativo praticado até então.

(6) Os autores agradecem aos financiadores das pesquisas. As informações sobre as pesquisa deverão ser complementadas após aprovação final do artigo, para que não haja identificação dos autores. 
(7) Parceria da Fipe com ZAP, para realizar monitoramento da evolução dos preços dos imóveis no mercado brasileiro. Informações sobre índices podem ser consultadas no site:http://fipezap. wpengine.com/.

(8) "Studios ou lofts" são termos em inglês utilizados pelas incorporadoras para se referir a apartamentos de um dormitório, com ambientes integrados, de pequena metragem quadrada, chegando a $14 \mathrm{~m}^{2}$ por unidade.

(9) O autor da pesquisa identificou, por exemplo, que paraguaios e haitianos pagam preços mais elevados de aluguel, que famílias de brasileiros, nos mesmo cômodos de cortiços da região central.

(10) Conforme entrevista realizada por Talita Anzei Gonsales, em janeiro de 2019.

(11) Os moradores contam com apoio de algumas lideranças mais antigas de movimentos de moradia na zona Sul, e a ocupação não foi articulada por um único grupo ou ator que aglutinou famílias, sendo assim, em termos de organização social, ainda está se estruturando.

\section{Referências}

BARBOSA, B. R. (2014). Protagonismo dos movimentos de moradia no centro de São Paulo: trajetória, lutas e influências nas políticas habitacionais. Dissertação de Mestrado. São Bernardo do Campo, Universidade Federal do ABC.

BONDUKI, N. (1998). Origens da habitação social no Brasil. São Paulo, Estação Liberdade.

COMARU, F. de A. (2013). Habitação social em áreas centrais e suas implicações para a saúde e acesso ao trabalho: hipóteses e uma agenda de pesquisas para o Brasil metropolitano. In: XV ENCONTRO NACIONAL DA ANPUR. Anais. Recife, v. 1, pp. 1-14.

EARLE, L. (2012). From insurgent to transgressive citizenship: housing, social movements and the politics of rights in São Paulo. Journal of Latin American Studies. Cambridge, fevereiro, pp. 97-126.

FERRARA, L. N. (2013). Urbanização da natureza: da autoprovisão de infraestruturas aos projetos de recuperação ambiental nos mananciais do sul da metrópole paulistana. Tese de Doutorado. São Paulo, Universidade de São Paulo.

HAESBAERT, R. (2004). O mito da desterritorialização: do "fim dos territórios" à multiterritorialidade. Rio de Janeiro, Bertrand Brasil.

HARVEY, D. (1980). A Justiça social e a cidade. São Paulo, Hucitec.

HOLSTON, J. e CARINA, C. (2013). Cidadania insurgente-disjunções da democracia e da modernidade no Brasil. São Paulo, Companhia das Letras, Capítulo 4, pp. 155-196.

KOHARA, L. (2013). As contribuições dos movimentos de moradia do centro para as políticas habitacionais e para o desenvolvimento urbano para o centro de São Paulo. Pesquisa de pós-doutorado. Relatório final. São Paulo, Fapesp e Fauusp.

KOWARICK, L. (1979). A espoliação urbana. Rio de Janeiro, Paz e Terra. 
LEFEBVRE, H. (1974). La production de l' espace. Paris, Anthropos.

(2001). O direito à cidade. São Paulo, Centauro.

MARICATO, E. (org.). (1982). A produção capitalista da casa (e da cidade) no Brasil industrial. São Paulo, Alfa-Omega.

(1988). A cidade é um grande negócio. Teoria e Debate. Disponível em: https://teoriaedebate. org.br/1988/06/15/a-cidade-e-um-grande-negocio/. Acesso em: 13 mar 2019.

(2008). O nó da terra. Revista Piauí. Edição 12, junho. Disponível em: https://piaui.folha.uol. com.br/materia/o-no-da-terra/. Acesso em: 13 mar 2019.

MARQUES, E. (2015). “Condições habitacionais e urbanas no Brasil”. In: ARRETCHE, M. (org). Trajetórias das desigualdades: como o Brasil mudou nos últimos cinquenta anos. São Paulo, Ed. Unesp e CEM, pp. 223-247.

MARTINS, M. L. R. R. (2005). Moradia e mananciais: tensão e diálogo na metrópole. São Paulo, FAUUSP/ Fapesp.

MARX, K. (1971). O capital (Crítica da economia política). O processo global de produção capitalista. Livro 3, v. 6. Rio de Janeiro, Civilização Brasileira.

MIRAFTAB, F. (2009). Insurgent planning: situating radical planning in the Global South. Planning Theory - Special Issue: Strangely familiar, v. 8, n. 1, pp. 32-50.

OLIVEIRA, F. (2013). "Entrevista Francisco de Oliveira”. In: BARROS, J.; DUARTE, L. e SILVA, E. B. (orgs). Caderno de debates 2. Cidades e conflitos: o urbano na produção do Brasil contemporâneo. Rio de Janeiro, Fase. Disponível em: https://fase.org.br/wp-content/uploads/2013/09/Caderno_de_ Debates_2.pdf. Acesso em: 2 dez 2018.

PARRA, A. e PASSARELLI, S. H. (2017) Dinâmicas culturais populares em centros urbanos: barreiras e motivações. In: XVII ENCONTRO NACIONAL DA ANPUR. Anais. São Paulo.

PASTERNAK, S. e D'OTTAVIANO, C. (2016). Favelas no Brasil e em São Paulo: avanços nas análises a partir da Leitura Territorial do Censo de 2010. Cadernos Metrópole. São Paulo, v. 18, n. 35, pp. 75-99.

PEREIRA, P. C. X. (2005). Dinâmica imobiliária e metropolização: a nova lógica do crescimento urbano em São Paulo. Scripta Nova. Revista electónica de geografía y ciências sociales, v. IX, n. 194(10). Barcelona, Universidad de Barcelona, 1ㅇ de agosto. Disponível em: http://www.ub.edu/geocrit/ sn/sn-194-10.htm. Acesso em: 14 jun 2019.

(2016). “A reprodução do capital no setor imobiliário e a urbanização contemporânea: o que fica e o que muda". In: PEREIRA, P. C. X. (org). Reconfiguração das cidades contemporâneas: contradições e conflitos. São Paulo, FAUUSP, pp. 125-138.

PREFEITURA DE SÃO PAULO (2010). Plano municipal da habitação: PMH 2009-2024. São Paulo, Secretaria Municipal de Habitação.

(2016). Plano Municipal de Habitação de São Paulo-Caderno para Discussão pública. Disponível em: http://www.habitasampa.inf.br/files/CadernoPMH.pdf. Acesso em: 22 jun 2019.

(2018). Situação das ocupações na cidade de São Paulo. São Paulo.

ROLNIK, R.; LEITÃO, K.; COMARU, F. e LINS, R. D. (coords.). (2017). Observatório de Remoções 2015 2017: Relatório final de projeto. São Paulo, FAUUSP. 
RUFINO, M. B. C. (2018). “Do zoneamento às Operações Urbanas Consorciadas: planejamento urbano e produção imobiliária na mercantilização do espaço em São Paulo (1970-2017)". In: PEREIRA, P. C. X. Imediato, global e total na produção do espaço: a financeirização da cidade de São Paulo no século XXI. São Paulo, FAUUSP.

SHIMBO, L. Z. (2012). Habitação social de mercado: a confluência entre Estado, empresas construtoras e capital financeiro. Belo Horizonte, C/Arte.

(2018). "Produção da habitação e espoliação na metrópole de São Paulo (1970-2010)". In: PEREIRA, P. C. X. (org). Imediato, global e total na produção do espaço: a financeirização da cidade de São Paulo no século XXI. São Paulo, FAUUSP, pp. 112-136.

TEIXEIRA, A. C.; COMARÚ, F. de A.; CYMBALISTA, R. e SUTTI, W. (2005). Conflitos em torno do direito à moradia na região central de São Paulo. Rio de Janeiro, lbase, ActionAid e Ford Foundation.

VAINER, C. B; BIENENSTEIN, R.; TANAKA, G. et al. (2013). O Plano Popular da Vila Autódromo: uma experiência de planejamento conflitual. In: XV ENCONTRO NACIONAL DA ANPUR. Anais. Recife.

ZILLIG, D. (2019). Transformação e valorização imobiliária na região do Arouche centro de São Paulo: estudos sobre tendências de gentrificação. Trabalho final de Graduação. Santo André, Universidade Federal do ABC.

Texto recebido em 14/dez/2018

Texto aprovado em 10/jan/2019 
